\title{
Antes de História e consciência de classe
}

RICARDO MUSSE

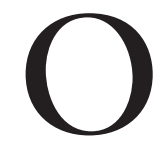

S COMENTÁRIOS sobre a obra de Georg Lukács, ou mais especificamente sobre História e consciência de classe (de 1923), em geral, iniciam a apresentação e a análise desse livro com a reconstituição do itinerário intelectual do autor. Assim, não deixam de pressupor que seus escritos pré-marxistas constituem uma espécie de chave mestra para a compreensão de sua trajetória posterior ou mesmo da gênese do marxismo ocidental. Essa premissa, no entanto, é frequentemente negada no próprio decorrer da exposição, uma advertência que sinaliza as aporias inerentes a tal perspectiva. Afinal, a par de uma preocupação comum com a compreensão da produção artística, suas obras de juventude discrepam bastante entre si, configurando um percurso marcado por sucessivas rupturas e por descontinuidades formais e metodológicas.

Seu primeiro livro, Evolução histórica do drama moderno (escrito em 19061907 e publicado em 1911), redigido ainda em húngaro, pode ser descrito como uma obra de sociologia literária composta sob o prisma de uma ordenação enciclopédica da cultura. ${ }^{1}$ Para compreender o trágico moderno - a forma peculiar adquirida pelo conflito entre a afirmação do indivíduo e a objetividade da vida social -, Lukács recorre a categorias como "despersonalização", “coisificação", “intelectualismo”, “racionalização” etc., peças proeminentes do arsenal conceitual da sociologia alemã. ${ }^{2}$

Em 1911, Lukács publica na Alemanha $A$ alma e as formas, coletânea de artigos redigidos entre 1908 e 1910, na qual incluiu alguns textos já editados na revista húngara Nyugat (Lukács, 1971). Abre o livro, à guisa de prefácio, uma carta a Leo Popper que pondera sobre o estatuto do ensaio, reconhecendo em sua forma autônoma - um âmbito distinto tanto da arte como da ciência e da filosofia - um potente instrumento para a apreensão da totalidade do fenômeno estético e da "vivência” que lhe é subjacente. ${ }^{3}$ Com essa defesa do ensaio, ele almeja não somente dirimir o viés reducionista dos estudos histórico-literários, mas, sobretudo, fornecer uma fundamentação teórica para a renovação da crítica cultural.

Apesar da heterogeneidade dos autores escolhidos como ponto de partida dos ensaios - Rudolph Kassner, Søren Kierkegaard, Novalis, Theodor Storm, Stefan George, Charles-Louis Philipee, Richard Beer-Hofmann, Laurence Sterne e Paul Ernst -, patente seja pelo ângulo da tendência estética, do período histórico ou mesmo da língua e nacionalidade; cristalizam-se no decorrer do 
livro vários fios comuns. O mais destacado deles talvez seja a reiteração da cisão que Lukács expressa por meio da duplicidade entre a "vida" e a "vida", matriz de uma série de dicotomias: o imediato e o autêntico, a vivência empírica e a essencial, o cotidiano e a existência plena. A mediação entre esses polos constitui a tarefa primordial da "forma artística", que se torna assim o objeto por excelência da investigação ensaística.

O programa proposto por Lukács (2008b, p.110), no entanto, extravasa o campo estético:

O crítico é aquele que vislumbra a fatalidade das formas, cuja vivência mais intensa é aquele conteúdo da alma que as formas, indireta e inconscientemente, escondem em si mesmas. A forma é sua maior vivência, ela é, como realidade imediata, o que há de figurativo, de verdadeiramente vivo em seus escritos. Da força dessa vivência essa forma, originada de uma observação dos símbolos da vida, recebe uma vida própria. Ela se torna uma visão de mundo, um ponto de vista, uma tomada de posição diante da vida da qual ela se originou: uma possibilidade de transformá-la e recriá-la.

Nessa direção, A alma e as formas procura desentranhar, em cada uma das manifestações literárias examinadas, a partir da observação da "forma artística", potenciais "formas de vida", nas quais transparecem determinações valorativas, escolhas éticas, indicações para a ação, experimentos utópicos que apontem à vida verdadeira.

Em seguida, instalado em Heidelberg, Lukács concentra-se na redação de uma teoria estética sistemática. ${ }^{4}$ Nesses fragmentos, adota como ponto inicial a existência de obras de arte para, em seguida, indagar sobre suas condições de possibilidade.

Esse modo de colocar a questão, ainda no âmbito da investigação transcendental, promove, no entanto, um deslocamento em relação ao modo como Kant examina o fenômeno estético na Critica da faculdade de julgar. Configura também uma ruptura radical com as premissas do neokantismo, movimento que Lukács rechaça a partir do veredicto de que suas análises não superam o estatuto de uma mera "metafísica do belo".

Além disso, sua estética desdobra considerações de $A$ alma e as formas acerca da especificidade, da autonomia e do caráter significativo da "forma artística". Esse movimento direciona sua reflexão para uma espécie de "fenomenologia" das obras de arte, atenta à apreensão do aparato formal que lhes é inerente.

Apesar da recepção entusiasmada do manuscrito por parte de Max Weber e de seus incentivos para que concluísse o trabalho, Lukács não hesita em interromper - com três capítulos rascunhados - essa tentativa de "filosofia da arte", para se dedicar integralmente ao projeto de um livro sobre Fiódor Dostoiévski. ${ }^{5}$

Com a irrupção da Primeira Guerra e o retorno do autor à Hungria, esse plano é abandonado. Os prolegômenos da obra esboçada, no entanto, foram agrupados e concentrados, no inverno de 1914-1915, em dois ensaios articulados publicados no ano seguinte na revista de Max Dessoir, Zeitschrift für allge- 
meine Kunstwissenschaft, e editados posteriormente como livro, em 1920, sob o título A teoria do romance.

Nesse volume, Lukács procura compreender a dimensão histórica das formas estéticas por meio de uma análise comparativa da essência dos gêneros literários no mundo antigo e no mundo moderno. Os pressupostos, os procedimentos e o próprio resultado conciliam, num híbrido, a tentativa de uma filosofia da história (impactada pelos temas da sociologia da modernização) com o esboço de uma tipologia do romance.

A grande épica, representativa do mundo grego, na reconstrução de $A$ teoria do romance, transcreve um universo "perfeito e acabado", no qual a imediatez da vida cotidiana ainda se apresenta como plenamente significativa. Nesse solo, os fins do indivíduo se confundem, harmonicamente, com o destino da coletividade:

Totalidade do ser só é possível quando tudo já é homogêneo, antes de ser envolvido pelas formas; quando as formas não são uma coerção, mas somente a conscientização, a vinda à tona de tudo quanto dormitava como vaga aspiração no interior daquilo a que se devia dar forma: quando o saber é virtude e a virtude, felicidade; quando a beleza põe em evidência o sentido do mundo. (Lukács, 2000, p.31)

O romance, "epopeia de um mundo abandonado por deus", em contraposição, desenvolve-se em uma sociedade que se organiza como uma segunda natureza, na qual prevalece a cisão entre as aspirações do indivíduo e a objetividade das relações sociais. Sua composição, estruturalmente problemática, denota o empenho em resistir à perda da imanência do sentido, à privação da "totalidade espontânea do ser", configurando-se como uma "busca para descobrir e construir, pela forma, a totalidade oculta da vida" (ibidem, p.60). ${ }^{6}$

O herói, no romance, apresenta-se como uma individualidade isolada, como uma subjetividade cujos estados de ânimo exprimem sua inadequação à vida convencional. Encontra-se condenado, num mundo em que "objetivo algum é dado de modo imediato", a perseguir incessantemente um sentido para a existência (ibidem, p.62). O caráter aporético de tal empreendimento é registrado na consciência narrativa como "ironia" - índice de "objetividade do romance" -, um recurso formal que "apreende não apenas a profunda desesperança dessa luta, mas também a desesperança tanto mais profunda de seu abandono" (ibidem, p.87).

Lukács constrói sua tipologia do romance adotando como diretriz duas modalidades distintas de inadequação do personagem em relação à vida corrente: "a alma é mais estreita ou mais ampla que o mundo exterior que lhe é dado como palco e substrato de seus atos" (ibidem, p.99). Privilegia assim uma explicação mais concentrada no exame de conteúdos do que na decomposição dos elementos formais do gênero, embora parta da pressuposição de que o romance, ao longo de seu processo de desenvolvimento, manteve sua forma exterior "essencialmente biográfica". 
Denomina a primeira situação de "idealismo abstrato", destacando já na terminologia a "rigidez da psicologia" do personagem. Engloba os casos em que o estreitamento da alma do herói, sua inaptidão para qualquer espécie de vivência interior restringe sua atividade à pura ação. Suas aventuras, atomizadas no espaço geográfico, extraem sua significação do embate entre o caráter estático de seu ideal e a realidade externa.

A outra modalidade, o "romantismo da desilusão", congrega personagens dotados, na estrita esfera da interioridade, de uma "vida própria e dinâmica", "repleta de conteúdo e mais ou menos perfeita em si mesmo" (ibidem, p.118). Com a rarefação da ação, resultante do pendor contemplativo do herói, predomina a análise psicológica, elevando ao ápice a importância intrínseca do indivíduo. O sentido e a própria configuração formal do romance derivam assim de uma incorporação consciente da temporalidade, sucedâneo da fabulação épica em um "mundo abandonado por deus".

O legado do jovem Lukács com sua diversidade de orientações assumiu, nos relatos estabilizadores e unificantes dos historiadores das ideias e dos intérpretes de sua obra, os contornos de um objeto atravessado por incoerências e contradições. Perspectiva acentuada seja pela evidente discrepância formal entre os projetos a que se dedicou - tratado de sociologia literária, ensaios de crítica cultural, fragmentos de reflexão filosófica, teoria histórico-filosófica dos gêneros literários -, seja por súbitas mudanças de registro cultural e de filiação, sinalizadas no decorrer de seu itinerário intelectual.

Na primeira década do século XX, Lukács, ainda que sob a influência da cultura alemã, insere-se e convive primordialmente no campo intelectual húngaro. Em 1902, estreia como crítico de teatro no jornal Magyar Szalon, uma experiência que durou poucos meses, mas delineou o rumo prosseguido com sua participação, em 1904, na fundação da Sociedade Thalia, uma tentativa bem-sucedida de atualização do movimento teatral de Budapeste. ${ }^{7}$ A partir de 1906, passa a publicar regularmente nas duas principais revistas da Hungria, Huszadik Század [Século XX] e Nyugat [Ocidente].

Em entrevistas e relatos autobiográficos, ele destacou seu entusiasmo, nessa época, com dois intelectuais contemporâneos, reconhecendo em suas obras e condutas modelos e fontes de inspiração: o poeta Endre Ady, por seu inconformismo e recusa obstinada em se reconciliar com a ordem social existente, e Ervin Szabó, expoente da ala esquerda que, inspirado no sindicalismo francês e em Georges Sorel, tentou chocalhar a passividade evolucionista do Partido Social-Democrata Húngaro (MSZP). ${ }^{8}$

Em 1911, Lukács transfere-se para a Alemanha. Depois de uma breve passagem por Berlin, durante a qual assistiu a cursos e entrou em contato com Georg Simmel, instalou-se em Heidelberg. Lá, integrou-se prontamente ao círculo que se reunia aos domingos na residência de Max Weber, uma congregação de inte- 
lectuais consagrados e jovens estudantes, frequentada, entre outros, por Ferdinand Tönnies, Werner Sombart, Georg Simmel, Alfred Weber, George Jellinek, Ernst Tröltsch, Wilhelm Windelband, Emil Lask, Friedrich Gundolf, Karl Jaspers, Franz Rosenzweig, Robert Michels, Ernst Bloch e Ernst Toller. ${ }^{9}$

Durante a guerra, convocado pelo serviço militar, retorna à Hungria, prestando serviços civis no exército. Em breve, é dispensado. ${ }^{10}$ Nesses anos, participa ativamente das discussões e da organização dos cursos oferecidos pela Escola Livre das Ciências do Espírito - instituição concebida e mantida por um grupo de intelectuais que cultivava a filosofia e a sociologia germânicas, alguns deles, como Lukács, retornando de temporadas de estudos na Alemanha. ${ }^{11}$

Nos prefácios que redigiu nos anos 1960, por ocasião da primeira reedição de suas obras de juventude, Lukács reconstitui seu percurso como uma "evolução dialética" do idealismo subjetivo (Kant) ao materialismo histórico (Marx), com uma estação de passagem no idealismo objetivo (Hegel). ${ }^{12}$ Segundo ele, todas as suas obras desse período, incluindo $A$ teoria do romance, foram concebidas conforme os métodos das Geisteswissenschaft [ciências do espírito] tendo como modelo os trabalhos de Dilthey, Simmel e Weber (Lukács, 2000, p.9). As diferenças entre elas devem ser atribuídas, sobretudo, às oscilações de suas inclinações filosóficas.

Nessa classificação, Evolução histórica do drama moderno e $A$ alma e as formas situam-se na primeira fase, período marcado por sua adesão estrita à "teoria neokantiana da imanência da consciência". ${ }^{13}$ A teoria do romance, por sua vez, assinala a transição do idealismo subjetivo ao objetivo, patente não apenas no empenho em aplicar os conceitos de Hegel às questões artísticas, como também no esforço de "historicização das categorias estéticas", embrião de uma tentativa de filosofia da história (Lukács, 2000, p.11-13). ${ }^{14} \mathrm{O}$ diagnóstico do presente, no entanto, sintetizado, em terminologia fichtiana, no emblema "a era da perfeita pecaminosidade" traduziria antes a influência de Kierkegaard do que um retorno a Fichte (ibidem, p.15).

Apesar de sua manifesta intenção de procurar evitar a composição de um "desenvolvimento intelectual imanente e orgânico" e de seu cuidado em indicar a presença simultânea de "oposições abruptas", seus relatos estão regidos por um telos, como se sua trajetória intelectual fosse a consecução ordenada de um projeto, ao que consta, inexistente na origem ou mesmo no decorrer do caminho. ${ }^{15}$ Assim, nos marcos dessa construção evolutiva, cada etapa passa a ser avaliada com o padrão de medida do resultado final, destacando a cada momento o grau de afastamento ou proximidade da "correta" compreensão do marxismo.

Outro traço característico desses textos autobiográficos, além da intensidade valorativa, consiste em sua preocupação em identificar desdobramentos de sua obra juvenil no corpo do "marxismo ocidental". Desse modo, Lukács, que acusou Bloch de invocar contra ele $A$ teoria do romance, no debate sobre o ex- 
pressionismo nos anos 1930, não deixa também - numa inversão especular - de colocar-se na mesma posição, que considerou "grotesca": ataca com certa dose de virulência seus primeiros livros, no propósito de assim minar a credibilidade de projetos intelectuais concorrentes. ${ }^{16}$

Nesse movimento, não hesita em minimizar a originalidade de seus primeiros trabalhos, apresentando-os como mero epigonismo de escolas e correntes filosóficas ou então como resultantes de uma mesma, homogênea e unilateral, "base sociofilosófica", o famigerado "anticapitalismo romântico". Subestima ainda o teor contestatório desses escritos ao sentenciar que são o produto de "uma fusão de uma ética de esquerda e de uma epistemologia de direita". Não espanta então que Lukács conclua o Prefácio de 1962 proclamando que a leitura de $A$ teoria do romance por quem busca orientação terá como resultado "uma desorientação ainda maior".

Em linhas gerais, parece mais factível, no entanto, conceber o itinerário do jovem Lukács como consequência de um empenho em dominar os gêneros predominantes no mundo acadêmico, concomitante ao esforço em incorporar em seu repertório autores e tendências culturais - um aprendizado obrigatório para quem buscava inserção e reconhecimento no campo intelectual da Alemanha guilhermista. ${ }^{17}$

Em outro registro, destacando a descontinuidade e o impulso repentino dessas rupturas, cabe observar que suas atitudes e interesses percorrem um trajeto que parece mimetizar o trânsito entre as "esferas" descrito na filosofia de Kierkegaard. ${ }^{18}$ Impactado pela barbárie da Primeira Guerra, Lukács "salta" do universo estético para o ético e em seguida para a ação revolucionária. ${ }^{19}$

A recapitulação de seus trabalhos anteriores certamente contribui para explicar a maturidade intelectual de História e consciência de classe, iluminar sua proficiência no terreno da filosofia e da sociologia alemã ou mesmo para atestar a precocidade de sua crítica à civilização burguesa. Porém, de modo geral, a dissecação do percurso intelectual do jovem Lukács pouco esclarece sobre as teses de sua primeira publicação marxista, alicerçadas na mudança de sua situação da condição de crítico cultural para a de militante político e, em princípio, orientadas por uma decidida tomada de posição no interior dessa linhagem.

A obra de Engels, a partir do Anti-Dübring, redigida em grande parte após a morte de Marx (1883), contribuiu para estabelecer como parâmetro de inserção na tradição do marxismo o esforço concomitante de divulgação, sistematização teórica e ampliação temática do materialismo histórico. ${ }^{20}$

Em Lukács, o empenho em atualizar o marxismo - empreitada renovada a cada geração tendo em vista o caráter assumidamente histórico dessa vertente - adquiriu contornos próprios. História e consciência de classe estabelece como critério de aferição da pertinência e validade de qualquer obra que se pretenda herdeira do legado de Marx a sua capacidade em desdobrar de forma articulada 
três tarefas, distintas e entrelaçadas: fornecer um diagnóstico do presente histórico, se posicionar ante a já extensa linhagem do marxismo e conceber uma interpretação original dos textos canônicos dessa doutrina.

História e consciência de classe se propõe, assim, a recuperar a capacidade autorreflexiva que o marxismo havia perdido nos anos de predomínio da Segunda Internacional. Nesse sentido, um de seus alvos principais consiste na codificação da dialética apresentada pelo último Engels, avaliada como uma das premissas dos equívocos políticos e intelectuais da geração subsequente. Não se trata apenas do fato de Engels, seguindo o panlogicismo de Hegel, estender a atuação da dialética ao reino da natureza, adotando as ciências naturais como regra e modelo. A sua principal crítica refere-se à desatenção ante o vínculo entre método e transformação do mundo, que tende a ignorar o papel da dialética como "álgebra da revolução" (cf. Musse, 2005).

Para além dessa correção metodológica, convém observar que História e consciência de classe se insere em outro cenário, moldado por novas circunstâncias históricas - entre as quais cabe destacar a sucessão de insurreições operárias que só foram derrotadas definitivamente alguns meses depois da publicação do livro, no outono de 1923 - que permitiram a Lukács vivenciar um contexto semelhante àquele que levou o jovem Marx a expor sua teoria como "expressão pensada do processo revolucionário".

\section{Notas}

I Lukács (1981), Entwicklungsgeschichte des modernen Drama. O livro comenta a dramaturgia, entre outros, dos seguintes autores: Lessing, Schiller, Goethe, Hebbel, Ibsen, Strindberg, Gerhart Hauptmann, Anton Tchékhov, Maurice Maeterlinck, Bernard Shaw, Oscar Wilde, Gabriele d'Annunzio e Hugo von Hofmannsthal. Um dos capítulos foi publicado, em 1914, na então mais prestigiosa revista acadêmica alemã, os Archiv für Sozialwissenschaft und Sozialpolitik, sob o título "Zur Soziologie des modernen Dramas".

2 Lukács destaca, entre suas leituras nesse período, a Filosofia do dinheiro, de Georg Simmel, e os textos de Weber sobre o protestantismo (cf. Lukács, 2008a, p.38).

3 Lukács (2008b), "Sobre a essência e a forma do ensaio: Uma carta a Leo Popper". Rejeitado em seguida pelo próprio autor, esse texto foi recuperado e desdobrado, quase meio século depois, em Adorno (2003), "O ensaio como forma".

4 O manuscrito, iniciado em Florença no inverno de 1911-1912, só veio a lume, em 1974, numa edição organizada por György Márkus e Frank Benseler, sob o título Heidelberger Philosophie der Kunst 1912-1914 (Lukács, 1974b). Para uma apresentação da "primeira" estética de Lukács, ver Tertulian (2008) e Almeida da Silva (2008).

5 Weber avaliava que esse texto, com sua pretensão sistemática, constituía a melhor opção que Lukács dispunha para desenvolver e apresentar como tese de habilitação, exigência obrigatória para o ingresso na carreira de professor na Universidade alemã. Embora contrariado, ele acabou aceitando a sugestão de Weber. A partir desse manuscrito, redigiu a tese com a qual pleiteou a habilitação em 25 de maio de 1918 junto à Universidade de 
Heidelberg. Apesar dos apoios, sua postulação foi recusada. A tese também só foi publicada postumamente, sob o título Heidelberger Ästhetik 1916-1918 (Lukács, 1974a).

6 “O romance é a epopéia de uma era para a qual a totalidade extensiva da vida não é mais dada de modo evidente, para a qual a imanência do sentido à vida tornou-se problemática, mas que ainda assim tem por intenção a totalidade" (ibidem, p.55).

7 Na entrevista autobiográfica Pensamento vivido, Lukács (1999, p.33-4) relata que além das tarefas de organização do grupo Thalia e da tradução para encenação de $O$ pato selvagem, de Ibsen -, ciente das insuficiências da crítica impressionista, dedicou-se nesse período ao estudo de obras teóricas, especialmente as de Kant, Dilthey e Simmel.

8 Apesar e talvez por conta dessa admiração, Lukács (1999, p.40-2) confessa que manteve escasso contato pessoal com eles.

9 Para um relato pessoal desses encontros e das opiniões de Weber sobre seus contemporâneos, ver Honigsheim (1968).

10 Décadas depois, Ernst Bloch intriga-se ainda com o fato de Lukács, um opositor declarado da guerra, ter acatado o alistamento militar (ver a entrevista concedida a Michael Löwy (1979, p.284-5) em Para uma sociologia dos intelectuais revolucionários). Em Pensamento vivido, Lukács (1999) esclarece que contava com a influência de seu pai, então diretor-presidente de um banco de crédito - e a corrupção vigente nas altas esferas da sociedade húngara - para conseguir sua liberação.

11 Ministraram conferências lá, além de Lukács, entre outros, Karl Mannheim, Arnold Hauser, Béla Balázs, Ervin Szabó, Béla Bartók, Eugene Varga e Béla Fogarasi.

12 Prefácio (1962) de A teoria do romance e Prefácio (1967) aos Frübschriften II (em Lukács, 2003, p.1-50). Nesses textos, Lukács desenvolve de forma pormenorizada a descrição esboçada em 1933 no artigo "Meu caminho para Marx” (Lukács, 2008a).

13 Lukács reconhece afinidades com Windelband, Rickert, Simmel e Dilthey, mas não com os pensadores da tendência que denomina "idealismo subjetivo extremo" - os neokantianos da escola de Marburgo e Ernst Mach (ver Lukács, 2008a, p.38).

14 Ele reconhece aí sua dívida para com a correspondência Schiller-Goethe, no que tange à questão dos gêneros literários, e de Friedrich Schlegel e Solger, no tratamento do conceito de ironia.

15 No Prefácio de 1967, ele destaca: "Se a Fausto é permitido abrigar duas almas em seu peito, porque uma pessoa normal não pode apresentar o funcionamento simultâneo e contraditório de tendências intelectuais opostas quando muda de uma classe para outra em meio a uma crise mundial?” (Lukács, 2003, p.4).

16 No Prefácio de 1962 para A teoria do romance, Lukács menciona explicitamente Jean-Paul Sartre, Ernst Bloch e Theodor W. Adorno.

17 Nos relatos autobiográficos, Lukács, conforme a conjuntura, ora ilumina ora joga sombra sobre os autores que leu. Em "Meu caminho para Marx" menciona Marx, Simmel, Weber, Dilthey, Windelband, Rickert, Hegel, Feuerbach, Szabó, Rosa Luxemburg e Lenin. No Prefácio de 1962, adiciona a esse catálogo Bergson, Friedrich Schlegel, Solger, a correspondência Goethe-Schiller, Kierkegaard, Bloch, Tolstói e Dostoiévski. O roteiro de Pensamento vivido completa a lista com o acréscimo de Paul Ernst, Mehring, Lessing, o romantismo de Iena, Schopenhauer, Nietzsche e Georges Sorel.

18 Kierkegaard (1986). Sobre a teoria das "esferas", ver também Adorno (2010, p.193231). 
19 Para uma descrição dos dilemas éticos de Lukács antes de aderir ao Partido Comunista ver Lukács (1979).

20 Para uma exposição do papel de Engels na gênese da tradição marxista, ver Musse (2000).

\section{Referências}

ADORNO, T. W. O ensaio como forma. In: Notas de literatura I. São Paulo: Editora 34; Duas cidades, 2003. p.15-45.

Kierkegaard: construção do estético. São Paulo: Editora Unesp, 2010.

ALMEIDA DA SILVA, A. A autonomia da obra de arte no jovem Lukács. Revista UFG, Goiânia, ano X, n.4, p.96-103, jan./jun. 2008.

HONIGSHEIM, P. On Max Weber. New York: Free Press, 1968.

KANT, I. Crítica da faculdade do juizo. Rio de Janeiro: Forense Universitária, 1993.

KIERKEGAARD, S. Ponto de vista explicativo de minha obra como escritor. Lisboa: Edições $70,1986$.

LÖWY, M. Para uma sociologia dos intelectuais revolucionários: a evolução política de Lukács (1909-1929). São Paulo: Editora Ciências Humanas, 1979.

LUKÁCS, G. Die Seele und die Formen: Essays. Neuwied; Berlin: Hermann Luchterhand, 1971.

. Heidelberger Ästhetik 1916-1918. Darmstadt; Neuwied: Hermann Luchterhand, 1974a.

Heidelberger Philosophie der Kunst 1912-1914. Darmstadt; Neuwied: Hermann Luchterhand, 1974b.

O bolchevismo como problema moral. In: LÖWY, M. Para uma sociologia dos intelectuais revolucionários. São Paulo: Editora Ciências Humanas, 1979. p.303-10.

Entwicklungsgeschichte des modernen Drama. Darmstadt; Neuwied: Hermann Luchterhand, 1981.

. Pensamento vivido: autobiografia em diálogo. São Paulo; Viçosa: Ad Hominem, Editora UFV, 1999.

. A teoria do romance. São Paulo: Editora 34; Livraria Duas Cidades, 2000.

. História e consciência de classe: Estudos sobre a dialética marxista. São Paulo: Martins Fontes, 2003.

. Meu caminho para Marx. In: Socialismo e democratização. Rio de Janeiro: Editora UFRJ, 2008a. p. 37-54.

Sobre a essência e a forma do ensaio: Uma carta a Leo Popper. Revista UFG, ano X, n. 4, p. 104-121, jan./jun. 2008b.

MUSSE, R. O primeiro marxista. In: BOITO JUNIOR, A. et al. A obra teórica de Marx. São Paulo: Xamã; IFCH-Unicamp, 2000. p.81-9.

. A dialética como discurso do método. Tempo Social, São Paulo, v.17, n.1, p.367-89, jan./jun. 2005.

TERTULIAN, N. Georg Lukács: etapas de seu pensamento estético. São Paulo: Editora Unesp, 2008. 


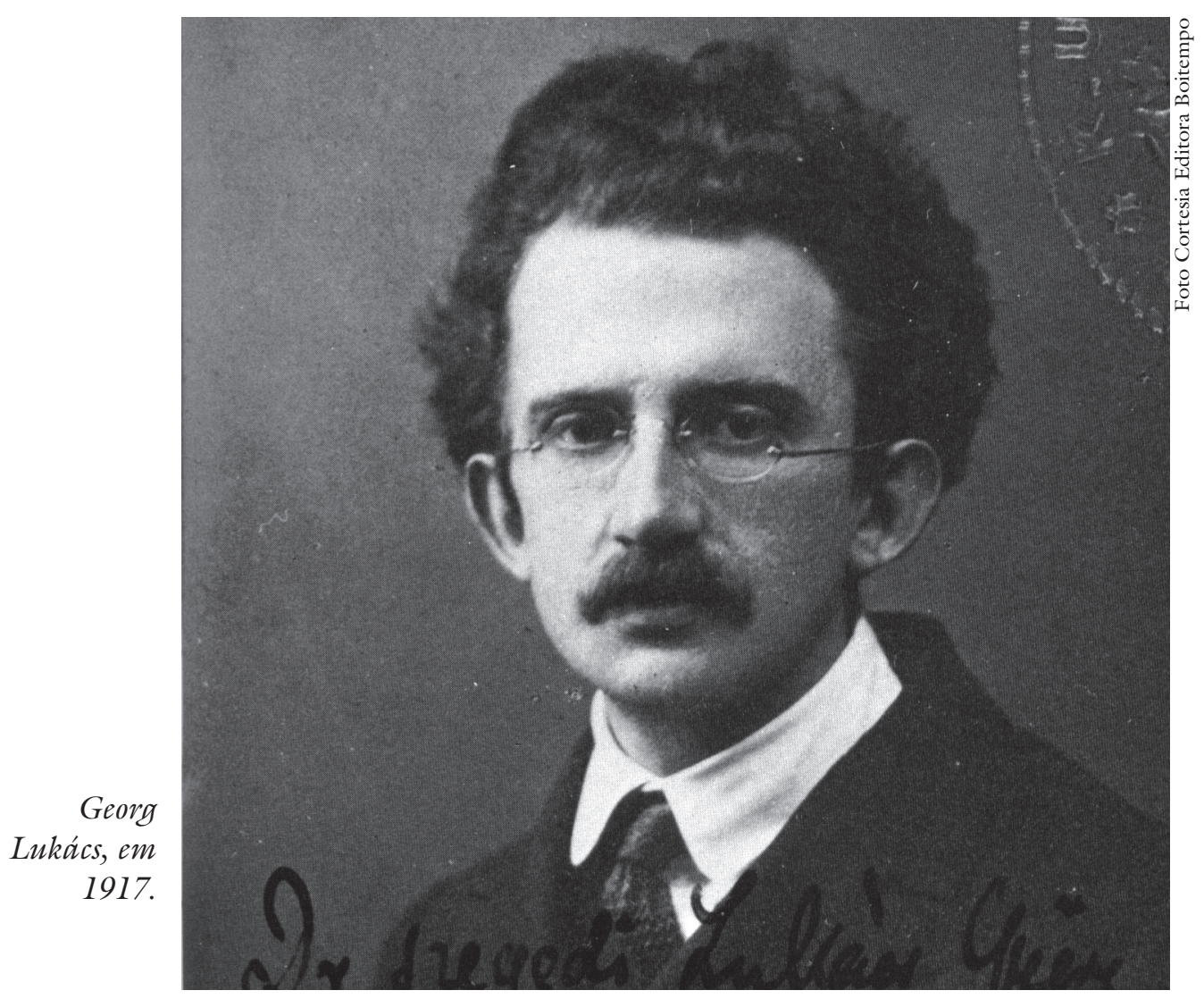

RESUMO - Apesar dos esforços dos comentadores em assinalar uma continuidade e uma presença da obra inicial de Georg Lukács em seu primeiro livro marxista, História e consciência de classe, um exame cuidadoso de seus primeiros livros e manuscritos desmente essa hipótese. Além da evidente discrepância formal patente em seus primeiros trabalhos, marcados por súbitas mudanças de registro cultural e filiação, esses textos inserem-se num empenho e num solo conceitual bastante distinto da adoção do marxismo consolidada em História e consciência de classe.

PALAVRAS-CHAVE: Jovem Lukács, Teoria do romance, História e consciência de classe.

ABSTRACT - Despite the efforts of commentators to point out a continuity and highlight a presence of the initial works of Georg Lukács in his first Marxist book, History and Class Consciousness, a careful examination of his early books and manuscripts disproves this hypothesis. Besides the obvious formal discrepancy found in his first works, e.g., the sudden changes in cultural persuasion and affiliation, these texts pertain to a commitment and a conceptual terrain entirely distinct from the adoption of Marxism consolidated in History and Class Consciousness.

KEYWORDS: Young Lukács, The theory of the novel, History and class consciousness.

Ricardo Musse é professor do Departamento de Sociologia da Faculdade de Filosofia, Letras e Ciências Humanas da USP. @ - rmusse@usp.br

Recebido em $1^{\circ}$.5.2013 e aceito em 21.5.2013. 